University of Nebraska - Lincoln

DigitalCommons@University of Nebraska - Lincoln

Drought Mitigation Center Faculty Publications Drought -- National Drought Mitigation Center

$1-24-2018$

\title{
IMPROVING NATIONAL AND REGIONAL DROUGHT EARLY WARNING SYSTEMS IN THE GREATER HORN OF AFRICA
}

Tsegaye Tadesse

Nicole Wall

Michael Hayes

Mark Svoboda

Deborah `Bathke

Follow this and additional works at: https://digitalcommons.unl.edu/droughtfacpub

Digitairt of the Climate Commons, Environmental Indicators and Impact Assessment Commons, Epmmpnental Monitoring Commons, Hydrology Commons, Other Earth Sciences Commons, and the Nettereresource Management Commons

Logo

This Article is brought to you for free and open access by the Drought -- National Drought Mitigation Center at DigitalCommons@University of Nebraska - Lincoln. It has been accepted for inclusion in Drought Mitigation Center Faculty Publications by an authorized administrator of DigitalCommons@University of Nebraska - Lincoln. 


\title{
MEETING SUMMARIES
}

\section{IMPROVING NATIONAL AND REGIONAL DROUGHT EARLY WARNING SYSTEMS IN THE GREATER HORN OF AFRICA}

\author{
Tsegaye Tadesse, Nicole Wall, Michael Hayes, Mark Svoboda, and Deborah Bathke
}

T he increased frequency and severity of droughts in Africa due to change in global climate necessitate the need for more effective drought planning and mitigation strategies. A key factor in reducing the negative impacts of these natural disasters and helping manage food security is improving national and regional drought early warning systems (DEWS) in the Greater Horn of Africa (GHA) through the development of seasonal hydroclimatic monitoring and prediction tools that are linked to action-oriented planning.

WORKSHOP OBJECTIVES. On $24-25$ October 2017, the National Drought Mitigation Center (NDMC), in collaboration with the National Meteorological Agency of Ethiopia, Entoto Observatory and Research Center, National Drought Management Authority of Kenya, and Ethiopian Meteorological Society, convened a participatory

affiliations: Tadesse, Wall, Hayes, SVoboda, and BathKeNational Drought Mitigation Center, University of NebraskaLincoln, Lincoln, Nebraska

CORRESPONDING AUTHOR: Dr. Tsegaye Tadesse, ttadesse2@unl.edu

DOI:10.1175/BAMS-D-18-0019.1

In final form 24 January 2018

C)2018 American Meteorological Society

For information regarding reuse of this content and general copyright information, consult the AMS Copyright Policy.

\section{THIRD PARTICIPATORY RESEARCH WORKSHOP ON SEASONAL PREDICTION OF HYDROCLIMATIC EXTREMES IN THE GREATER HORN OF AFRICA}

WHAT: The workshop was conducted to discuss various new and existing seasonal models and experimental drought and vegetation prediction products with experts and decision-makers representing local (private, governmental, and nongovernmental organizations), regional, and international organizations in the Greater Horn of Africa (GHA). Eighty-five participants met to discuss a strategic approach for improving drought early warning and food security systems in the GHA.

WHEN: 24-25 October 2017

Where: Addis Ababa, Ethiopia

research workshop in Addis Ababa, Ethiopia. This workshop was the third in a series held to support a National Aeronautics and Space Administration (NASA)-funded project to improve seasonal prediction of hydroclimatic extremes in the GHA. Collaborators included Johns Hopkins University, the University of Wisconsin-Madison, the University of California, Santa Barbara, Columbia University, the U.S. Geological Survey, NASA, and experts across the GHA. Eighty-five participants (including project researchers, operational seasonal forecasters, forecast users, and decision-makers) attended. While some participants also attended the first and second 
workshops held in 2014 and 2015 (Tadesse et al. 2016), an effort was made to broaden participation to include national and regional climate information users and representatives from agricultural, water management, and disaster management sectors.

The objectives of this workshop were to 1) present the outcomes of the NASA-GHA project (including various seasonal models and experimental drought and vegetation prediction products) to participants and collect their feedback, 2) discuss how to interpret and deliver seasonal prediction information to improve DEWS and identify an implementation strategy, and 3) identify human and financial resources that could help in implementing the new prediction tools to improve the current early warning systems in GHA. To meet these objectives, the workshop engaged participants via breakout group discussions and surveys. The workshop presentations are available online (http://drought .unl.edu/NewsOutreach/Outreach/Workshops /NASAEthiopia2017.aspx).

IMPROVING NATIONAL AND REGIONAL DEWS. Institutional support for improving DEWS comes from the establishment and improvement of a national drought policy and plan. The Integrated Drought Management Programme (IDMP 2015) created the three key "pillars" that are principles which every drought plan and policy at all scales should consider. These pillars are 1) drought monitoring and early warning systems, 2) vulnerability and risk assessment, and 3) drought preparedness, mitigation, and response. The first pillar includes tracking drought indicators/indices based on climate and biophysical variables, such as precipitation, temperature, soil moisture, vegetation condition, streamflow, and groundwater. The second pillar consists of the assessment of social, economic, and environmental factors or processes that increase the susceptibility or resilience of a system to drought impacts. The third pillar comprises any structural or physical measures (such as crops, dams, and engineering projects) and nonstructural measures (such as policies, awareness, knowledge development, public commitment, legal frameworks, and operating practices) that are undertaken to limit the adverse impacts of drought.

Breakout sessions were used to discuss the three key pillars of drought preparedness plan and identify ways in which the hydroclimatic seasonal prediction tools could be incorporated into the three-pillars concept. All of the workshop attendees (85) were fairly evenly distributed among three sectors- agriculture; water; and disaster preparation, response, or recovery-and primarily represented agencies and higher academic institutions in Ethiopia, Kenya, Tanzania, Sudan, Norway, and the United States. Participants were encouraged to join the breakout group most relevant to their sector. Additionally, 46 out of 85 (54\%) workshop participants completed a survey at the end of the workshop. Most of the participants filling out the survey were from Ethiopia (26 out of 46 or $57 \%$ ).

\section{BREAKOUT GROUP DISCUSSIONS.}

Breakout groups during the workshop were tasked with identifying gaps, challenges, and opportunities related to linking seasonal prediction tools to drought and flood management activities and decisions. The group in the disaster management sector noted that challenges exist because the pillars have been perceived as mainly a top-down information flow pattern in the GHA. Additionally, huge gaps in weather and climate information exist between what is needed at the local level and what is being produced at the global or regional levels. Thus, for the three pillars to be effective, stakeholders in the GHA should be coordinated with the climate service value chain, which ranges from climate data acquisition and analysis to interpretation, communication, and use. To address monitoring and early warning needs under mitigation and response, the agriculture and water sectors cited the main themes of needing more local data, analysis and value-added climate information at a local level, data management, and forecasts and outlooks.

The agriculture sector noted that Ethiopia is establishing "drought stakeholder platforms" that include national meteorological and agricultural representatives. Currently, needs exist for better accuracy in drought monitoring, tied to recommendations of the need for emergency seed, livestock feed, and water. In terms of human capital, the Agro-weather Advisory Service (Ethiopia) will be responsible for working with groups involved in climate/agriculture. Outreach materials will be produced, including agrometeorological advisory guidelines and training. One participant in the disaster management group cited the need for a country assessment about what type of plan should be included in the national policy. The role of indigenous knowledge is very important and should be integrated (noted by a representative from Sudan). In addition, for disaster management, mitigation and adaptation should be better defined (currently, various definitions exist). Generally, in disaster 
management, response and mitigation services include the provision of emergency services and public assistance during or immediately after a disaster. Both adaptation and resettlement can be part of mitigation. Apart from the structural measures, mitigation includes legal frameworks, land-use planning, incentives, training and education, public awareness, public participation in preparedness programs, and institutional building. In the GHA, planning at local, regional, and national levels exists but mitigation and response plans need to be strengthened. For instance, most drought plans/ policies are adequate in disaster management but the implementation is weak. Therefore, contingency planning is needed, and the mitigation and response actions have to be connected with early warning systems at local, national, and regional levels.

Feedback related to the third pillar and how early warning can help mitigate impacts indicated that farmers are the most vulnerable in the GHA. Further research should be done to determine the most vulnerable areas, collect information from the government and farmers, and establish basic guidelines and methodologies for vulnerability assessments. In Ethiopia, the government does vulnerability assessments for disaster responses (e.g., food aid) by using forecasts by the National Meteorology Agency. Through the lens of disaster risk management, early warning and planning information can help identify and rank areas that are sensitive to disaster (e.g., marginalized pastoral lands). Specific impacts for disaster risk management include migration issues, such as decreased water levels, low cattle prices, energy and water rationing, and conflict resolution in water-scarce regions (e.g., pastoral areas). The participants concluded that disaster risk reduction or risk treatment can be addressed through risk avoidance (e.g., relocation and land-use regulation), risk control (e.g., irrigation), risk transfer (e.g., crop and livestock insurance), and risk retention (e.g., self-insurance).

CHALLENGES AND SURVEY RESULTS. The survey at the end of the workshop had a good sector representation: 29 (63\%) represented the agriculture sector; 14 (30\%) represented the disaster preparation, response, and recovery sector; and 8 (17\%) individuals represented the environmental quality sector. Other sectors represented were health, hydropower, irrigation development, water supply, community organizations, and policy. The academic research and meteorology operations sector was also represented (15\%).
The breakout groups' discussion and evaluation survey at the end of the workshop indicated several challenges in improving the drought early warning systems in the GHA. Most of the respondents are concerned about the ever-increasing dry periods or drought and extreme rains or flooding. It was pointed out that the impacts of these disasters are exacerbated by man-made factors, such as land degradation and deforestation, insect-borne diseases or illnesses in humans and/or livestock, and groundwater depletions. Population growth in the GHA also exacerbates the impacts of drought.

When asked why decision-makers may not use climate information, 29 out of $46(63 \%)$ indicated lack of skill for processing and/or incorporating the information at a local scale. The responses include lack of understanding (50\%), overall uncertainty (22\%), and lack of trust (35\%) in using climate information. In addition, Internet access/availability across the GHA was noted as a possible obstacle. More than half (63\%) of the survey respondents were advisors on making decisions using climate information. Among the respondents, 19 (41\%) were providers of climate information, $9(20 \%)$ were users of climate information for their decision-making, and 44 out of 46 (97\%) were fairly experienced with some level of drought monitoring and early warning information. These respondents indicated that the new and improved seasonal drought monitoring tools would help early warning systems in the GHA. However, there should be strong collaborative efforts to incorporate the new seasonal tools (e.g., training the local experts, especially on how to use this information at the local level). Figure 1 shows the climate information flows for drought early warning in the GHA that could leverage the existing systems in building efficient DEWS.

RECOMMENDATIONS. Agricultural sector survey respondents reported the need for improved early warning systems (including seasonal hydroclimatic prediction tools and weather information for routine decisions) and seasonal drought and flood information to inform timing of land preparation, planting, and harvest. Some suggestions included integration of indigenous knowledge. Another suggestion for future development was improving communication mechanisms for sharing information with collaborators and the public. Respondents also identified a need for long-term climate projections to inform investments, such as irrigation development and drought planning. Because lack of financial resources is one of the main challenges, resource mobilization, strong involvement 
of the private sector, and investment in drought risk management are necessary to build a proactive and resilient region. In addition, social issues related to race, class, and gender need to be addressed to improve DEWS and build proactive and drought-resilient communities.

Last, participants indicated that they would want to help incorporate the outcomes/tools of this project to move forward in the DEWS of the GHA. The key factors for future op-

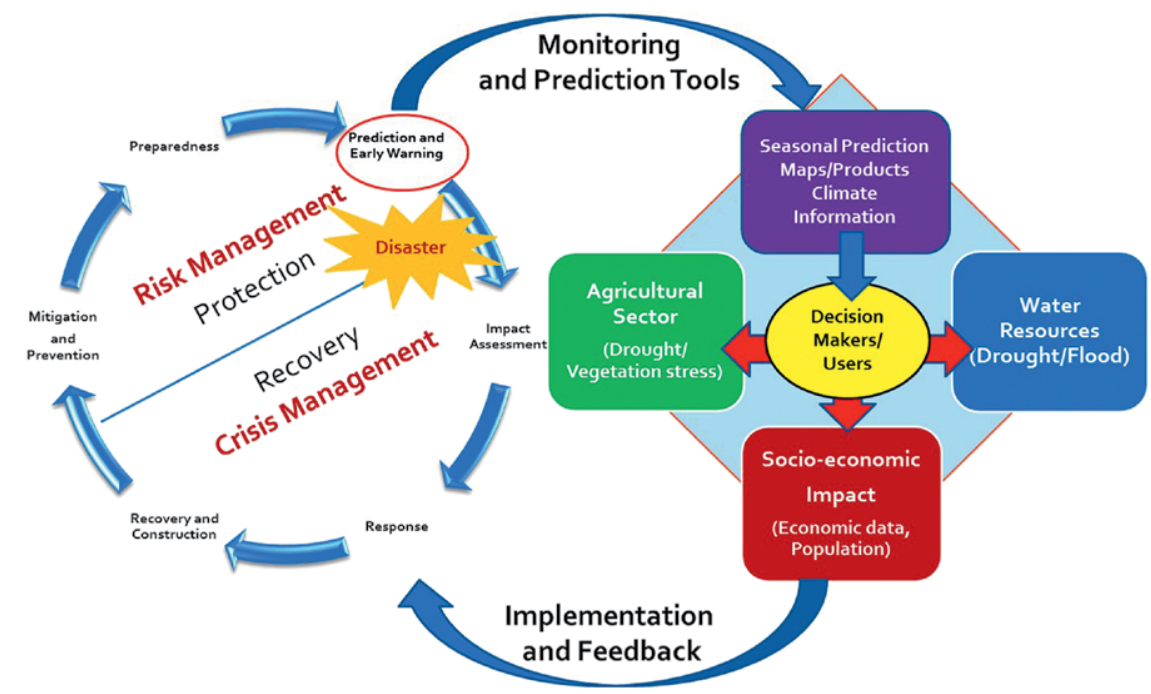

FIG. I. Climate information flows for drought early warning in the GHA. erations include pathways for better data sharing, formal collaborations, and communication that involves more stakeholder engagement. Building more human capital in drought risk management was mentioned as key to future operations related to this DEWS effort.

ACKNOWLEDGMENTS. The workshop was supported by the University of Nebraska-Lincoln. The project is funded by NASA under Grant Agreement NNX14AD30G. The authors thank the members of the organizing committee for their help in planning and executing the workshop, as well as all the speakers and attendees for their participation.

\section{REFERENCES}

IDMP, 2015: Drought Risk Management Scheme-A decision support system. Integrated Drought Management Programme Tech. Note, accessed 15 January 2018, 13 pp., www.gwp.org/globalassets/global/gwp -cee_files/idmp-cee/idmp-act-5.4-technical-note.pdf. Tadesse, T., T. Haigh, N. Wall, A. Shiferaw, B. Zaitchik, S. Beyene, G. Berhan, and J. Petr, 2016: Linking seasonal predictions into decision-making and disaster management in the Greater Horn of Africa. Bull. Amer. Meteor. Soc., 97, ES89-ES92, https://doi.org/10.1175 /BAMS-D-15-00269.1. 